\title{
DETERMINANTS OF PRO-ENVIRONMENTAL BEHAVIOUR AMONG STUDENTS
}

\author{
DHIYA HILLMAN FADZIL*, MOHD YUSOFF YUSLIZA AND ABDUL HAFAZ NGAH
}

Faculty of Business, Economics and Social Development, University Malaysia Terengganu, 21030 Kuala Nerus

*Corresponding author: dhiyahillman@gmail.com

http://doi.org/10.46754/umtjur.2021.04.009

\begin{abstract}
This paper examines the determinants of pro-environmental behaviour among university students. It uses the theory of planned behaviour in determining the factors that lead to such behaviour. The determinants consist of environmental awareness, psychological factors (motivation, moral norms, perceived behavioural control and attitude), environmental knowledge and personality traits (agreeableness, extroversion, conscientiousness, neuroticism and openness to experience). Data was collected using convenience sampling through self-administered surveys and online forms distributed to 400 students in a public university in Malaysia. Data was subjected to construct validity and reliability analysis. The findings highlighted that motivation, agreeableness and perceived behavioural control were positively related to the practice of pro-environmental behaviour, whereas environmental awareness, moral norms, attitude and environmental knowledge were negatively related. Some personality traits, namely neuroticism, openness to experience, conscientiousness and extraversion, did not show any significant relationship with the practice of pro-environmental behaviour. This study provides a scope to improvise and incorporate environmental practices into the habits of students by aligning their goals with the universities' dimensions, including curriculum, campus operation, research and outreach activities. The results could make an important contribution in establishing a sustained green culture through a new university paradigm.
\end{abstract}

Keywords: Pro-environmental behaviour, environmental awareness, environmental knowledge, psychological factors, students

\section{Introduction}

Making the human environment more viable is one of the biggest problems of the $21 \mathrm{st}$ century; with arguments abound on the core of sustainable societies as an ecological way of life achieved by environmental actions (Kollmuss \& Agyeman 2002). Based on previous study, environmental management has been identified as one of the most important issues in society because it has many direct and indirect effects on human life (Stuart et al., 2009).

Green universities are expected to contribute the most to environmental sustainability (Yuan et al., 2013). Based on this understanding, proenvironmental behaviour (PEB) among humans may be regarded as an important personal endeavour, as the actions addressed are proven to be among the few main reasons for the occurrence of environmental problems (Chen et al., 2017). Lozano et al. (2015) proposed that dedicated universities (e.g. charters, posters, programmes, regulations) appear to be highly interested in a sustainable establishment than undedicated universities. Nonetheless, due to the lack of supporting research, it cannot be determined whether ecologically dedicated universities have contributed more than traditional higherlearning institutions in their sustainability results. Lozano's (2015) statement implied that ecological institutions are experiencing a stagnant trend, undertaking little effort to further green themselves or incorporating a few more environmental regulations as part of their academics. Nejati and Nejati (2013) mentioned that it may not be enough to just incorporate green practices into the campus as part of the curriculum. 
Emanuel and Adams (2011) stated that realistically, students are one of the university's largest stakeholders who will generate a prominent impact on environmental sustainability. They do express a desire to participate in and support sustainable environmental practices in their campuses. The determinants of student PEB have also been studied by several researchers (Cotton et al., 2016; Ting \& Cheng, 2017). This study tries to explore the following questions:

Question 1: Does the students' environmental awareness lead to PEB?

Question 2: Do psychological factors lead to PEB?

Question 3: Does the students' environmental knowledge lead to PEB?

Question 4: Do personality traits lead to PEB?

The purpose is to criticize the relationship between environmental awareness, knowledge, psychological factors, personality traits and the practice of PEB among students.

\section{Literature Review}

\section{Pro-environmental Behaviour}

Different researchers have varying terms in explaining certain behaviours, such as environmental responsibility, environmental actions and environmental-friendly acts. Proenvironmental action is a practice that provides less danger towards the environment, which helps to enhance the ecosystem tremendously, albeit deliberately (Steg \& Vlek, 2009).

\section{Environmental Awareness}

The term is interpreted as an ecological medium that consists of one's perception, its values and action towards nature (Browne et al., 2011). The components of environmental awareness include knowledge of the environment and recognition of its current issues (Hurst et al., 2013). Evidence indicates that environmental awareness potentially possesses the key motivation for an active ecological lifestyle.
Interchangeably, environmental awareness may become a mechanism for ecological actions (Asilsoy et al., 2017)

\section{Motivation}

A motivated person is characterised as an energised or stimulated individual (De Leeuw et al., 2015). Conversely, it may be defined as experiencing a realistic path of preserving the environment while possessing excess energy to perform it. Both provided prominent initiatives for the motivation and capacity of individuals to carry out pro-environmental acts (Fadeeva et al., 2010). Greenwood (2013) argued that activitybased instruction, including active learning, is beneficial and more effective as an inspiration for students to achieve ecological sustainability.

\section{Moral Norms}

Moral norms define a person's ability to recognize righteousness in various behaviours. Delaney and White (2015) implied that actions which required more effort to carry out will usually be considered morally upright, and the principles of those activities will be desired by more individuals. Braun and Dierkes (2016) indicated that professional development may generate unpleasant emotions of guilt and ethical correctness, which may then act as a constructive stimulus for sustainability behaviours.

\section{Perceived Behavioral Control}

People who accept good interpersonal influence behavioural regulation feel that they are able to drive outcomes. A person with high levels of leadership, confidence and influence is more likely to exhibit patterns of PEB engagement than someone with lower level of skills and beliefs (De Leeuw et al., 2015). Han and Yoon (2015) further suggested that perceived behavioral control will contribute to the engagement of environmental practices. Few findings show that in the context of active learning, there is a transition in perceived behavioural control of participants that causes them to attempt to alter the environment (Savageau, 2013). 


\section{Attitude}

Attitude is viewed as a psychological propensity articulated by assessing the expectations (or perspectives) of the natural world with some extent of benefit or detriment, including factors influencing their consistency (Milfont 2009). Bamberg (2003) demonstrated that environmental perceptions have a causative role as a central indirect predictor of environmental actions after generating a clear interpretation of the circumstances.

\section{Environmental Knowledge}

Environmental knowledge is described as the capacity to recognize a variety of symbols, principles and trends of action relevant to the setting (Laroche et al., 2001). People who listen more about ecological concerns and consumption expenditure are often likely to act in a pro-environmental way (Oguz et al., 2010).

\section{Agreeableness}

Agreeableness deals with the behaviour of an individual in interacting with others (Mondak, 2010). Caring people tend to give more and build stronger social relationships (Mooradian \& Swan, 2006). Individuals who scored the highest on this attribute are polite, pleasant, constructive, supportive and kind who, in turn, will inspire others to practice green actions.

\section{Extroversion}

Extroverted individuals are highly engaging, joyful, energetic, enthusiastic, proactive, expressive, sociable, person-oriented, exciting and influential (Ekinci \& Dawes, 2009). Lower scores on this attribute suggest social rejection, a propensity to remain silent, and extreme prudence that may affect green behaviour. Extroverted people will favour interpersonal relationships similar to pleasant people (Mooradian \& Swan, 2006).

\section{Conscientiousness}

Conscientious individuals are accountable, coordinated and efficient, besides acting with a conscience. They are also prompt, careful and successful (Singh \& Singh, 2009). High scorers on this attribute have a tendency to be successful in completing their duties (Barrick \& Mount, 1991), illustrate positive contact with the others (Ekinci \& Dawes, 2009), and desire to create long-term connections that trigger environmental actions (Turky1lmaz et al., 2015).

\section{Neuroticism}

This is associated with emotional stability to maintain a comfortable, controlled and protected environment (Ekinci \& Dawes, 2009). Neuroticism, on the other hand, coincides with a person's ability to stay out of circumstances that need power and a propensity to think more, and to display lower proficiency in controlling emotions (Freitag \& Bauer, 2016).

\section{Openness to Experience}

Innovative, visionary, transparent, ambitious, intelligent and critical are typical traits of openmindedness (Erdheim et al., 2006). Open people are more accepting of both positive and negative experiences than closed individuals, and they tend to prefer more variety (McCrae \& Costa, 2003). Closed individuals value routines and convenience (Turky1lmaz et al., 2015). Several studies have reported that individuals who are extremely innovative are more likely to embrace something different, including sustainable actions (Adjei \& Clark, 2010).

\section{Hypothesis}

H1: Environmental awareness is positively related to the practice of PEB;

H2: Motivation of oneself is positively related to the practice of PEB;

H3: Moral norms are positively related to the practice of PEB; 
H4: Perceived behavioural control of oneself is positively related to the practice of PEB;

H5: Attitudes of an individual are positively related to the practice of $\mathrm{PEB}$;

H6: Environmental knowledge is positively related to the practice of $\mathrm{PEB}$;

H7: An individual who is agreeable is positively related to the practice of $\mathrm{PEB}$;

H8: An extroverted individual is positively related to the practice of $\mathrm{PEB}$;

H9: An individual who is highly neurotic is positively related to the practice of PEB;

H10: An individual's conscientiousness is positively related to the practice ofPEB; and,

H11: An individual who is open to all kinds of experiences is positively related to the practice of PEB.

\section{Materials and Methods}

\section{Sampling and Procedures}

Data was collected from students at Universiti Malaysia Terengganu in Kuala Terengganu, Terengganu, Malaysia, through online forms between March and May 2020. Selection of respondents is done by applying convenience sampling on a pool of 400 students. Sample size was determined according to Sekaran and Bougie (2010), which indicated that a sample size of between 30 and 500 respondents would be appropriate. Meanwhile Kline (2011) suggested a sample size of between 150 and 400 .

\section{Measures}

\section{Pro-environmental behaviour}

A set of questions adapted from Blok et al. (2015) discussed the relevant scope of practicing PEB, such as recycling, energy-saving light usage, printing and others. Students were asked to rate the relevance of those practices in their lives based on a five-point Likert scale, where the lowest point indicated that a behaviour was "never practiced" while the highest point showed that it was "always practiced" in the students' lives.

\section{Environmental Knowledge}

The five-point Likert scale was also used to rate the respondents' perception on environmental issues. The lowest 1-point in the scale referred to "Strongly Disagree", whereas the highest 5-point indicted the strongest agreement to a statement on the environment that they live in. Some examples of statements include: "I know about the problem of environmental pollution caused by human activities in the university's premises" and "I can see with my own eyes that the environment is deteriorating", which were adapted from Safari et al. (2018).

\section{Psychological Factors}

Several questions were adapted from previous studies to include psychological components, which were moral norms (Ruepert et al., 2016), motivation (Tian et al., 2019), perceived behavioural control (Swaim et al., 2013) and attitude (Blok et al., 2015). The five-point Likert scale was again used to rate the response, where 1-point represented strong disagreement and 5-point represented strong agreement. Questions were adapted for university purposes as to parallel with the main purpose of this study.

\section{Environmental Awareness}

Environmental awareness statements were adapted from Asilsoy et al. (2017). The five-point Likert scale was used with 1-point representing "Strongly Disagree" whereas 5-points were represented as "Strongly Agree". The statements included current issues like "I can briefly describe the global warming and climate change that is happening".

\section{Personality Traits}

Personality trait questions were taken from the "Big Five" questionnaire designed by Mayfield et al. (2008) to measure every trait. In response to each item, the five-point Likert scale was used with (1) indicating a strong disagreement and (5) a strong agreement. 


\section{Measurement Model}

The measurement model was first assessed for convergent validity by observing the loadings, average variance extracted (AVE) and composite reliability (CR) (Hair et al., 2020; Ramayah et al., 2018). As mentioned by Hair et al. (2020), which suggested that for assessing Confirmatory Composite Analysis (CCA), these were the three crucial criteria to be fulfil. Based on the analysis, the loadings were acceptable, and the AVE was higher than 0.5. CR, meanwhile, was also higher than 0.7. However, the second order factor PEB (AC, Drinking, Light, Printing, Recycling and Shopping) recorded an AVE of 0.277 and CR of 0.710, which was lower than the AVE criteria stated by Hair et al. (2020). Thus, the instruments used were valid and reliable.

The discriminant validity was further assessed according to the suggestion by Franke and Sarstedt (2019) in observing the heterotraitmonotrait (HTMT) ratio. The HTMT ratio should be lower than 0.90 for the lower limit and 0.85 for the upper limit. Results demonstrated that all HTMT ratios were lower than 0.85 , thus indicating that the measures were distinct. All the measures were valid and reliable as confirmed by both convergent and discriminant validity test.

\section{Results and Discussion}

A total of 300 respondents returned their questionnaires, giving an overall usable response rate of 75 per cent. Of the total, 63 per cent were females while 37 per cent were males. A majority of respondents was aged between 22 and $24(70.7 \%)$, followed by those aged between 19 and $21(25.0 \%)$. A small percentage was above 28 years old (1.0\%). Most respondents were students from the Faculty of Business, Economics and Social Development (FPEPS), which comprised $73.0 \%$ of the total, followed by students from the Faculty of Ocean Engineering Technology and Informatics (FTKKI) $(9.0 \%)$, Faculty of Maritime Studies (FPM) (21.0\%), Faculty of Fisheries and Food Sciences (FPSM) $(18.0 \%)$, and Faculty of Science and Marine Environment (FSSM) (15\%).
Atotal of 11 determinants of PEB were tested, of which motivation $(\beta=0.251, \mathrm{t}=2.458, \mathrm{p}<$ $0.05)$, perceived behavioural control $(\beta=0.260$, $\mathrm{t}=3.230, \mathrm{p}<0.01)$ and agreeableness $(\beta=0.132$, $\mathrm{t}=1.682, \mathrm{p}=0.047)$ were positively related to PEB, while environmental knowledge, moral norms, attitudes, environmental awareness, extraversion, neuroticism, conscientiousness and openness to experience were found to be insignificantly related. Thus, $\mathrm{H} 2, \mathrm{H} 4$ and $\mathrm{H} 7$ were supported, while $\mathrm{H} 1, \mathrm{H} 3, \mathrm{H} 5, \mathrm{H} 6, \mathrm{H} 8, \mathrm{H} 9$, $\mathrm{H} 10$ and H11 had to be rejected.

First, people who tended to agree with or accept the opinion of others were inclined to practice PEB. A highly agreeable person tended to behave in a manner that encouraged meaningful experiences with others, which demonstrated how compassionate people behaved. A cooperative attitude would inspire other people and raise their awareness on climate issues. Being warm and thoughtful for others could extend their caring attitude to the environment.

Second, regarding motivation, which was positively related to the practice of $\mathrm{PEB}$, a motivated person would carry out eco-friendly acts more than those who did not. When individuals behaved for their own intent, they dominated their own acts and choose their own desired outcomes on how to attain them.

Lastly, the findings showed that perceived behavioural control was linked to PEB. Individuals who had good perceived internal behavioural regulation appeared to think that they had the power to influence the consequences. Individuals with a high level of conviction, trust and influence would display an inclination towards PEB compared to those with a lower level of capacity to believe. The results suggested that perceived behavioural control was crucial in stimulating a person to act proenvironmentally.

\section{Conclusion}

Today, university students have become a strong medium of change for the environment. 
One of the most significant subjects of ecological studies is to describe the behaviour of individuals towards climate change, which in addition to theoretical importance, is also of practical value (Jurdi-Hage et al., 2019). To attract students as an educated class in society to practice $\mathrm{PEB}$, we need to create an appropriate mechanism for the development of such actions. We need science and technical expertise to build and sustain the new world. If students believe that environmental concerns may affect their personal lives and take responsibility for the planet, they may have more ecological pursuits to achieve. In fact, perceived behavioural control provides a direct connection to both intention and ecological behaviour. This indicates that the practice of environmental behaviour not only relies on moral norms, but also on students' understanding of their abilities to perform an action. In other words, as students become more empowered to carry out environmental activities, their purpose in life will be more aligned with environmental behaviours.

Knowledge and understanding are the most important tools to preserve our environment. A stable climate and clean water, air and soil form the basis of a sustainable environment. Clearly, these fundamental building blocks of life are important and must be maintained and improved. As awareness is the main driver for action, environmental education becomes vital as humans engage the world around them and encourage their children to do the same.

\section{Acknowledgements}

The authors wished to thank the university for the research opportunity and the reviewers for the constructive comments.

\section{References}

Adjei, M. T., \& Clark, M. N. (2010). Relationship marketing in A B2C context: The moderating role of personality traits. Journal of Retailing and Consumer
Services, 17(1), 73-79. DOI: 10.1016/j. jretconser.2009.10.001.

Bamberg, S. (2003). How does environmental concern influence specific environmentally related behaviors? A New answer to an old question. Journal of Environmental Psychology, 23(1), 21-32. DOI:10.1016/ S0272-4944(02)00078-6.

Barrick, M. R., \& Mount, M. K. (1991). The big five personality dimensions and job performance: A meta-analysis. Personnel Psychology, 44, 1-26. DOI:10.1111/j.1744-6570.1991.tb00688.x.

Blok, V., Wesselink, R., Studynka, O., \& Kemp, R. (2015). Encouraging sustainability in the workplace: A survey on the proenvironmental behaviour of university employees. Journal of Cleaner Production, 106, 55-67.

Braun, T., \& Dierkes, P. (2016). Connecting students to nature-how intensity of nature experience and student age influence the success of outdoor education programs. Environmental Education Research, 23(7), 1-13.

Browne, L. P., Garst, B. A., \& Bialeschki, M. D. (2011). Engaging youth in environmental sustain- ability: Impact of the camp 2 grow program. Journal of Park and Recreation Administration, 29(3), 70-85.

Buket, A., Selin, L., Sinem, Y., Kozan, U., \& Özge Ö. (2017). Environmental awareness and knowledge among architecture students in North Cyprus. International Journal of Educational Sciences, 19, 2-3, 136143, DOI: $10.1080 / 09751122.2017 .1393957$.

Chen, H., Chen, F., Huang, X., Long, R., \& Li, W. (2017). Are individuals' environmental behavior always consistent - An analysis based on spatial difference. Resources, conservation \& recycling, 125, 25-36 composite analysis. Journal of Business Research, 109, 101-110. https://doi. org/10.1016/j.jbusres.2019.11.069.

Cotton, D., Shiel, C., \& Paco, A. (2016). Energy saving on campus: a comparison of 
students 'attitudes and reported behaviours in the UK and Portugal. Journal of Cleaner Production, 129, 586-595. doi. org/10.1016/j.jclepro.2016.03.136.

de Leeuw, A., Valois, P., Ajzen, I., \& Schmidt, P. (2015). Using the theory of planned behavior to identify key beliefs underlying pro-environmental behavior in high-school students: Implications for educational interventions. Journal of Environmental Psychology, 42, 128-138. DOI: 10.1016/ j.jenvp.2015.03.005.

Delaney, M. F., \& White, K. M. (2015). Predicting people's intention to donate their body to medical science and research. The Journal of Social Psychology, 155(3), 221237.

Ekinci, Y., \& Dawes, P. L. (2009). Consumer perceptions of frontline service employee personality traits, interaction quality, and consumer satisfaction. The Service Industries Journal, 29(4), 503-521. DOI:10.1080/02642060802283113

Emanuel R., \& Adams, J. N. (2011). College students' perceptions of campus sustainability. International Journal of SustainabilityinHigherEducation, 12(1),7992. doi.org/10.1108/14676371111098320

Erdheim, J., Wang, M., \& Zickar, M. J. (2006). Linking the Big Five personality constructs to organizational commitment. Personality and Individual Differences, 41(5), 959-970. DOI:10.1016/j.paid.2006.04.005

Fadeeva, Z., Mochizuki, Y., Brundiers, K., Wiek, A., \& Redman, C. L. (2010). Real-world learning opportunities in sustainability: From classroom into the real world. International Journal of Sustainability in Higher Education, 11(4), 308-324

Franke, G., \& Sarstedt, M. (2019). Heuristics versus statistics in discriminant validity testing: A comparison of four procedures. Internet Research, 29(3), 430-447. https:// doi.org/10.1108/IntR-12-2017-0515.

Freitag, M., \& Bauer, P. C. (2016). Personality traits and the propensity to trust friends and strangers. The Social Science Journal, 53(4), 467-476.

Greenwood, D. A. (2013). What is outside of outdoor education? Becoming responsive to other places. Educational Studies, 49(5), 451-464.

Hair, J. F., Howard, M. C., \& Nitzl, C. (2020). Assessing measurement model quality in PLS-SEM using confirmatory composite analysis. Journal of Business Research, 109, 101-110. https://doi.org/10.1016/j. jbusres.2019.11.069.

Han, H., \& Yoon, H. J. (2015). Hotel customers' environmentally responsible behavioral intention: Impact of key constructs on decision in green consumerism. International Journal of Hospitality Management, 45(February), 22-33.

Hurst, M., Dittmar, H., Bond, R., \& Kasser, T. (2013). The relationship between materialistic values and environmental attitudes and behaviors: A meta-anal-ysis. Journal of Environmental Psychology, 36, 257-269.

Jurdi-Hage, R., Hage, H., \& Chow, H. (2019). Cognitive and behavioural environmental concern among university students in a Canadian city: Implications for institutional interventions. Journal of Environmental Education, 35, 28-61.

Kollmuss, A., \& Agyeman, J. (2002). Mind the gap: Why do people act environmentally and what are the barriers to pro-environmental behavior? Environmental Education Research, 8(3), 239-260.

Laroche, M., Bergeron, J., \& Barbaro-Forleo, G. (2001). Targeting consumers who are willing to pay more for environmentally friendly products. Journal of Consumer Marketing, 18, 503-520.

Lozano, R., Ceulemans, K., Alonso-Almeida, M., Huisingh, D., Lozano, F. J., Waas, T., Lambrechts, W., Lukman, R., \& Hug, J. (2015). A review of commitment and implementation of sustainable development 
in higher education: results from a worldwide survey. Journal of Cleaner Production, 108, 1-18 doi.org/10.1016/j.jclepro.2014.09.048

Mayfield, C., Perdue, G., \& Wooten, K. (2008) Investment Management and Personality Type. Financial Services Review, 17, 219236.

McCrae, R. R., \& Costa, P. T. Jr. (2003). Personality in adulthood: A five-factor theory perspective. Guilford Press, New York.

Milfont, T. L. (2009). The effects of social desirability on self-reported environmental attitudes and ecological behaviour. The environmentalist, 29(3), 263-269. DOI:10.1007/ s10669-008-9192-2.

Mondak, J. J. (2010). Personality and the foundations of political behavior. New York, USA: Cambridge University Press. Mooradian,

Mooradian, T. A., \& Swan, K. S. (2006). Personality-and-culture: The case of national extraversion and word-of-mouth. Journal of Business Research, 59(6), 778785. DOI: 10.1016/j.jbusres.2006.01.015.

Nejati M., \& Nejati, M. (2013). Assessment of sustainable university factors from the perspective of university students. Journal of Cleaner Production, 48, 101-107. doi. org/10.1016/j.jclepro.2012.09.006.

Oguz, D., Çakci, I., \& Kavas, S. (2010). Environmental awareness of university students in Ankara, Turkey. African Journal of Agricultural Research, 5, 2629-2636.

procedures. Internet Research, 29(3), 430-447. https://doi.org/10.1108/IntR-12-2017-0515

Ramayah, T., Cheah, J., Chuah, F., Ting, H., \& Memon, M. A. (2018). Partial least squares structural equation modelling (PLS-SEM) using SmartPLS 3.0: An updated guide and practical guide to statistical analysis (2nd ed.). Kuala Lumpur, Malaysia. Pearson.

Ruepert, A., Keizer, K., Steg, L., Maricchiolo, F., Carrus, G., Dumitru, A., Garcia-
Mira, R., Stancu, A., \& Moza, D. (2016). Environmental considerations in the organizational context: A pathway to pro-environmental behaviour at work. Energy Research \& Social Science, 17, 59. 10.1016/j.erss.2016.04.004.

Safari, A., Salehzadeh, R., Panahi, R., \& Abolghasemian, S. (2018). Multiple pathways linking environmental knowledge and awareness to employees' green behavior. Corporate Governance, 18(1), 81-103. https://doi.org/10.1108/CG-082016-0168

Savageau, A. E. (2013). Let's get personal: Making sustainability tangible to students. International Journal of Sustainability in Higher Education, 14(1), 15-24.

Singh, A. K., \& Singh, A. P. (2009). Does personality predict organisational citizenship behaviour among managerial personnel. Journal of the Indian Academy of Applied Psychology, 35(2), 291-298.

Steg, L., \& Vlek, C. (2009). Encouraging proenvironmental behaviour: An integrative review and research agenda. Journal of Environmental Psychology, 29(3), 309317. DOI: http://dx.doi.org/10.1016/j. jenvp.2008.10.004.

Stuart, A., Mudhasakul, S., \& Sriwatanapongse, W. (2009). The social distribution of neighborhood-scale air pollution and monitoring protection. Journal of the Air and Waste Management Association, 59, 591-602.

Swaim, J., Maloni, M., Napshin, S., \& Henley, A. (2013). Influences on student intention and behavior toward environmental sustainability. Journal of Business Ethics, 124(3), 465-484. Retrieved from www.jstor.org/stable/24033283

Tian, G., Wang, J., Zhang, Z., \& Wen, Y. (2019). Self-efficacy and work performance: The role of work engagement. Social Behavior and Personality: An International Journal, 47(12), e8528. 
Turkyilmaz, C. A., Erdem, S., \& Uslu, A. (2015). The effects of personality traits and web- site quality on online impulse buying. Procedia-Social and Behavioral Sciences, 175, 98-105. DOI:10.1016/j. sbspro.2015.01.1179.

Yuan X., \& Zuo J. (2013). A critical assessment of the Higher Education for Sustainable
Development from students' perspectives -A chinese study. Journal of Cleaner Production, 48, 108-115 doi.org/10.1016/j. jclepro.2012.10.041 
